\title{
OCCUPANTS' ENGAGEMENT FOR INDOOR AIR QUALITY OF MIDDLE INCOME HOUSING IN JAKARTA-INDONESIA
}

\author{
*Dyah Nurwidyaningrum ${ }^{1}$, Haryoto Kusnoputranto ${ }^{2}$, and Setyo Sarwanto Moersidik ${ }^{3}$ \\ ${ }^{1}$ Departement of Civil Engineering, Politeknik Negeri Jakarta, Indonesia; \\ ${ }^{2}$ Departement of Environmental Health, Faculty of Public Health, University of Indonesia, Indonesia; \\ ${ }^{3}$ Departement of Civil Engineering, Faculty of Engineering, University of Indonesia, Indonesia
}

*Corresponding Author, Received: 09 March 2020， Revised: 27 March 2020， Accepted: 23 April 2020

\begin{abstract}
The construction of middle-income housing in the city is an efficient way to land and to optimize the carrying capacity of the environment. The air quality condition of Jakarta City is still strived to be better, and this condition will certainly affect the health of the population in housing. In urban vertical housing, air conditioners become necessary equipment because they can regulate air circulation, and reduce pollutants from indoor to outdoor. The pollution, such as bad smell and poisonous gas, that comes from a neighboring unit can affect the comfort of the other units. The purpose of this research is to assess the occupants' engagement that influences the community implementing the indoor air quality (IAQ) sustainability in middle-income housing in Jakarta. This research is conducted by identifying the characteristic of occupants: managers and residents, exploring the occupants' interaction when applying healthy living habits in this middle-income housing, and analyzing the occupant's participatory relationships in optimizing the indoor air quality. The partial least squares method via SmartPLS is used for the research analysis. The result of the analysis shows that the involvement of both residents and managers is needed for developing healthy lifestyles, which affect the IAQ in the middle-income housing units. This suggests that the local government of Jakarta needs to make the community engagement program a requirement in the middle-income housing development regulations to support the administrative, technical, and ecological requirements for health sustainability.
\end{abstract}

Keywords: Occupant engagement, Middle-income housing, Indoor air quality, SmartPLS

\section{INTRODUCTION}

Many studies have shown that community engagement for implementing behavior change is very effective at improving health in a residential area [1,2]. Unfortunately, these studies still address issues related to implementing health in communities of horizontal settlement areas where the condition of its utilities and spaces management is not as complex as in vertical settlements [2]. In fact, it is not easy to encourage the community to become involved in a program without them receiving the direct benefits [3,4]. In the case of improving daily residents' behavior, it takes great effort from individuals and regulators and much initial capital. A preliminary study showed that vertical settlements are generally preferred by people from different region who have different behavioral characters [5]. They usually have different cultural background that affects buildings' circumstances. Another study states that the human dimension plays a role in the social processes of global environmental change, economic change, and cultural change [6]. The occupants and the managers are some of the persons that influence the energy-related behaviors over the building life cycle [7]. Therefore, the cooperation and good relationships between residents and managers determine the condition of the indoor air quality in middle-income housing.

It becomes a challenge for managers of vertical housing to influence the residents to behave well in their units and not affect their neighbors. The indoor air quality problems are generally not realized by the actor and will affect their neighbors. The theory of Community Building and Engagement Core Programmatic activities [8] states there must be driven approaches to strengthen the relationships among neighbors and catalyze positive community change. Community participation is the involvement of the community that is essential to reduce disaster vulnerability, to facilitate recovery after a disaster, and to stimulate community organization as the basis for sustainable development [9]. Thus, a study that emphasizes the role of managers in encouraging residents to behave appropriately in vertical dwellings is important. Therefore, the extent that managers' interests are involved in community engagement for indoor air quality sustainability in middle-income housing is necessary. 
The literature review shows that the effectiveness of community engagement is a defined approach to population and health behavior change [10]. According to this statement, healthy behavior will not be successful without the involvement of all participants. Another study argues that initiatives may be shared by participants [11], but some of them feel obliged and experience effects from physical, psychological, and financial stress impacts. Therefore, the Alberta Association [12] states that recommendations apart from the community involvement approach should be adopted to achieve the population interest and health behavior targets. Furthermore the potential adverse effects that affect community involvement initiatives should be considered. For that reason, the community-based organization (CBO) that is involved in engagement initiatives and the community involvement approach should be evaluated.

Therefore, this study focused on the occupant's health engagement for indoor air quality (IAQ) sustainability using manager encouragement as the driving variable between resident behavior and IAQ. The purpose of this study was to identify the influence of manager encouragement on residents'behavior to improve the IAQ in their units. This study compared the differences in the influence of the manager dimension on IAQ in residents' units with and without manager encouragement. The result of this comparison showed that there were different values for the influence on IAQ in the units. Before discussing the result, this paper shows how characteristics of each resident and manager, so the reader can see the need for their engangement for improving IAQ in this apartment.

The novelty of this study is that the encouragement of managers became the intellectual capital that could improve good social behavior for residents to participate in optimizing the IAQ. It is necessary that the residents are careful to avoid actions that may cause pollutants and that managers sincerely meet the physical and psychological comfort requirements through the expected communication. The residents with health encouragement from managers would participate in optimizing the IAQ in a high rise building if they felt their human dimensions were well satisfied by managers and thus they were easily encouraged to do good deeds for others. SmartPLS can be used for exploratory research, to investigate how the manager encourages the residents' engagement.

\section{METHODS}

The location of this study is one of middleincome housing area in central Jakarta $\left(-6.162^{\circ}\right.$ SL, $\left.106.745^{\circ} \mathrm{EL}\right)$. The area is 2.9 ha and $80 \%$ of the land is covered by a shopping center, transportation terminal, restaurants, and parks. Over $75 \%$ of the building facilities had been completed when this study started, except for an elementary school. In Jakarta, vertical housing is divided into two types: (a) housing that is leased to the local government who provides the subsidy for its development (rusunawa) and (b) apartment buildings owned by a private company for middle to high-income society (rusunami). This study was conducted on the rusunami type of middle-income housing. The facts showed that this middle-income housing had been inhabited for just 5 years and the manager was a new company engaged in the management of high rise housing. At the time the study began, this apartment had no owner and resident associations.

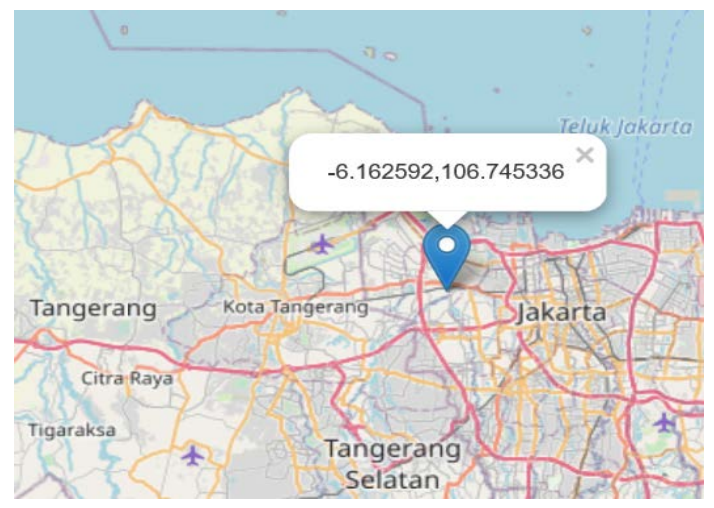

Fig. 1. The Housing Location

The 45 participants were those who were occupying two towers. The residents' requirements in this study were people who had lived for more than a year in their unit and were above the age of sixteen years old. The participants were determined purposively to be representative of almost every floor of the building. Each unit was represented by a participant. One unit consisted of 1 to 4 people and the units were mostly couples. Generally, unit is $33 \mathrm{~m}^{2}$ wide and consists of 2 bedrooms, 1 living room, and 1 bathroom. The total number of resident participants was 60, and the manager participated as well. The data collection was conducted from June to October 2017. It was the dry season with the IAQ at the comfort limit and 
the maximum temperature in order to reveal the boundary of service satisfaction.

This study used a mixed-method design. The qualitative approach applied a phenomenological study, staying in the apartment for approximately two weeks. This study obtained an interaction between the residents and the employees of the manager-the finding used for developing the questionnaires for quantitative research. The inquiries took a five-point Likert scale (1-5) for grouping the residents' and managers' responses. Moreover, IAQ meter data was used to confirm the result of residents' and managers' questionnaires. Then, all of the quantitative data analyzed used the partial least square (PLS) with the SmartPLS 3.2 program to find the inner model value. The SmartPLS analysis used the comparative method for looking at the difference with manager engagement.

The independent variables were the residents' dimensions and the managers'dimensions, while the dependent variable was the IAQ in the residents' units. The residents' dimensions consisted of four indicators: psychological comfort, physical comfort, healthy life participation, and polluting activities [12]. The Psychological comfort and physical comfort were the residents' basic needs variables, while healthy life participation and polluting activities were the dimensional influences of occupants on the IAQ in the residents' units. The managers' dimensions also had four indicators: inspecting, motivating, organizing and serving. The IAQ in residents' units was formed from two indicators: chemical and physical pollutants. The determination of the interval values of the IAQ in residents' units, used regulation number 1077 of the Ministry of Health of the Republic of Indonesia.

\section{RESULTS AND DISCUSSION}

Two bedrooms type is this apartment dominant type and the separation between rooms using a thin wall $(8 \mathrm{~cm})$ effectively. With this wide, it is possible the smell and gas went through rooms and spread to neighbors, especially cooking activity. The family with kids sometimes play in the corridor. Some staffs of managers periodically (2-3/week) visit the residents' unit to discipline the stuff that in front of units for reducing danger situation to safe evacuation and handle light residents' complaints. The residents can say heavy complain by phone. This wide type is a study result by an apartment investor consultant for a reliable price. On the contrary, this type makes residents do activities strictly, and unfortunately, the managers do not give transparent planning, so the residents do not feel engaged. Knowing the characteristic of the residents and managers of this apartment would show their engagement potency.

\subsection{Characteristics of Residents}

The customer service data show that 53\% are permanent residents and that they have lived there for more than 4 years. These permanent residents come from several tribes in Indonesia who work in the city of Jakarta and are mostly from Java, Sundanese, and Betawi. Most of them are young families, while some are other couples that have children and elderly couples.

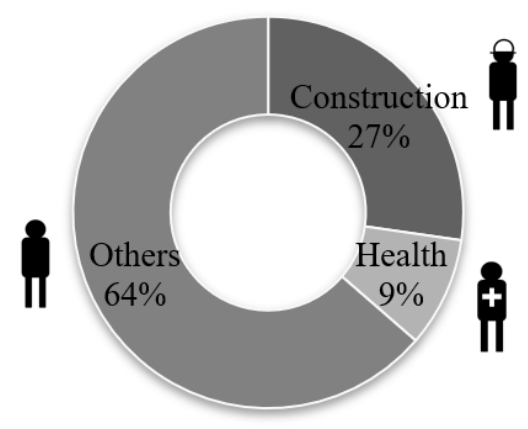

(a) The Residents Occupation

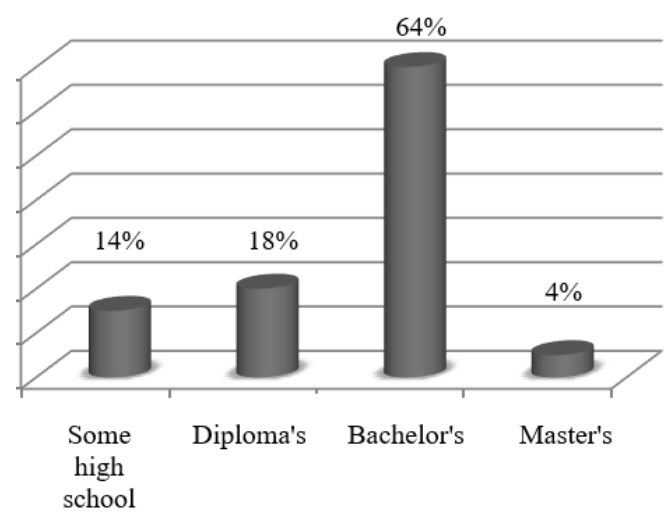

(b) The Education Background

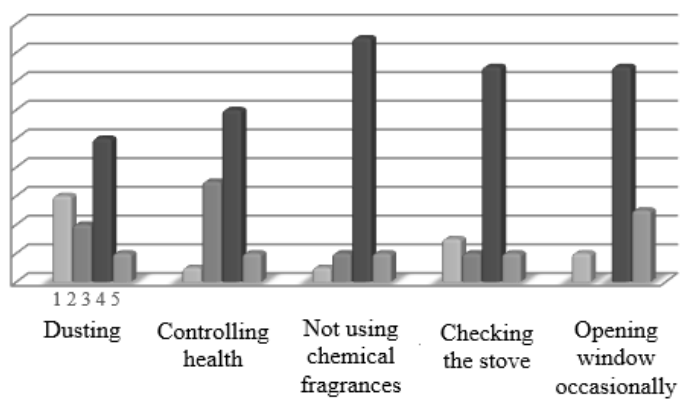

(c) The Healthy Behaviors

Fig. 2. The Characteristic of the Residents

Most of the participants prefer to live close to their workplaces and their daily activities. They prefer a practical life with supporting facilities in 
the apartment building, such as a food court, a laundry, cleaning services, and online transportation. The age interval of the resident participants was from18-56 years old and most were young employees that were18-37 years old. They had good education and were employees with various occupations. To discuss health awareness and IAQ participation, the participants were grouped based on their occupations, health educations, and activities that affect the IAQ.

Figure 2(a) shows that $38 \%$ of participants had health and construction occupations that were related to IAQ. Approximately 9\% of participants had occupations in the health area, and $27 \%$ had occupations in construction. The remaining $64 \%$ had no work related IAQ knowledge. Occupation can contribute to health care engagement [13], so there are residents who have the potential to improve the quality of the health in the building. The phenomenology data showed that the residents' occupations were related to their health behavior.

Figure 2(b) reveals that most participants have a good level of education. Out of all residents, $64 \%$ of them graduated with a bachelor's degree, $18 \%$ graduated with a diploma's degree, and 4\% graduated with a magister's degree. Only $14 \%$ of the participants completed some high school. Most participants are well-educated and generally receive sufficient income. According to the effects of age on intensity and the priority of life needs [14], with their educations and young and productive ages, they need physiological fulfillment, safety, a sense of belonging, and love. In Indonesia, diploma's and bachelor's degree graduates are categorized as level 4-6 and are able to work as executors and analysts who have the critical power to solve the the problems according to PERMENDIKTI number 44. Thus, they are critical people and are easily encouraged to achieve healthy lives. In the next discussion, on the PLS analysis, the education level is not a moderator variable because in this study the education level of the participants is good, so it does not have a significant influence in the PLS analysis.

Figure 2(c) indicates that the residents' knowledge of healthy behaviors is good enough to maintain the IAQ. Most participants have a value of 4 on the Likert scale. Regarding the 5 aspects of the assessment, the knowledge not to use hazardous chemicals is the highest among the aspects, followed by dusting, checking their routine health, checking the stove, and opening windows in the morning. This shows that participants were concerned with the health of their units [15]. However, there was still some participant that did not dust regularly and control their family health.

\subsection{Characteristics of Managers}

The company data reveal that the managers are from a new company in the apartment management fields that is one of the contractor's subsidiaries. The implementation of service activities indicates that managers are still slow at responding to resident complaints and tend to be careful in the economic calculations of services. The ratio of managers to residents is 1:5, meaning that one manager serves five residents.

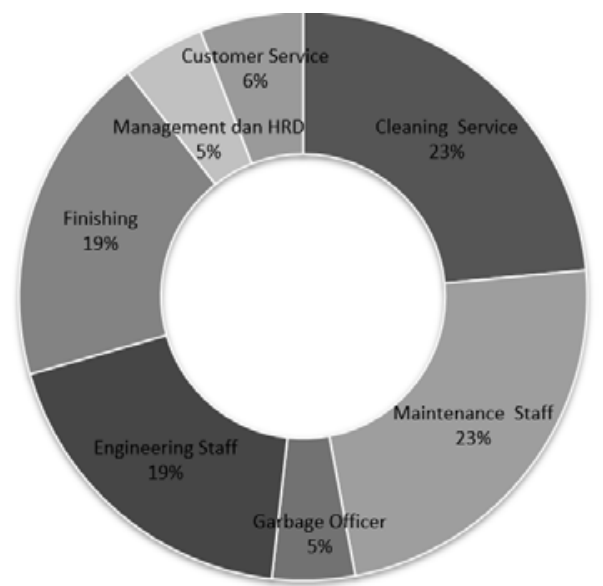

(a) The Managerial Position

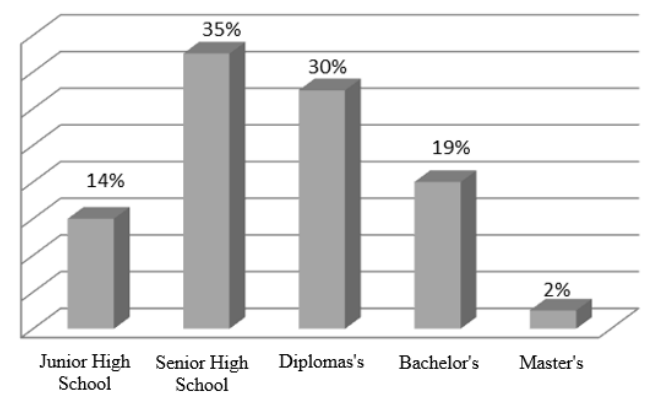

(b) The Education Background

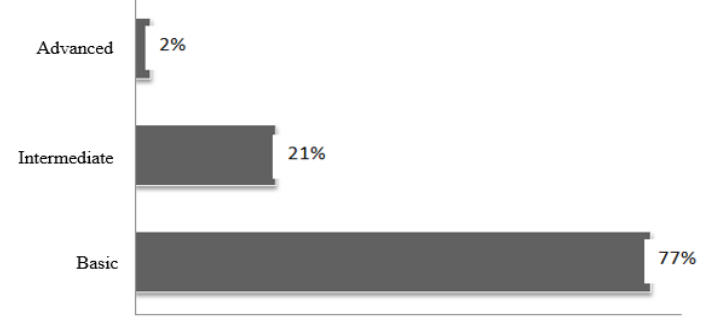

(c) The Training Level

Fig. 3. The Characteristic of the Managers

The participating managers generally have worked for 1-6 years with this company. Figure 3(a) shows the configuration of the position of the participating managers. Most of the participants are cleaning service and 
maintenance staff at 23\% each. Finishing and engineering staffs are at the second (19\%) and the third (18\%) positions, respectively. Additionally, $7 \%$ are in marketing, $5 \%$ are in management including customer service, and 5\% are garbage collectors. The data show that customer services occupy a very small percentage, even though it is very necessary to provide services to residents. A study [14] on exploring residents' satisfaction with the facilities provided by private apartment companies reveals that there is a strong relationship between the services provided by private companies and the number of customer services. Related to this case study, the number of customer services determines the residents' satisfaction.

Figure 3(b) presents the education level of managerial staff. Most of the participants completed some senior high school (35\%) or a diploma's degree (30\%). Most of others have a bachelor's degree (19\%) or completed some junior high school (14\%). Master's degree graduates are only $2 \%$, even though they are the decision makers. The data show that this percentage is unbalanced because the managers should have better education levels to serve residents.

In terms of management competence, the training levels of the participants are shown in figure 3(c). Figure 3(c) shows the advanced level is achieved by $2 \%$ of managers. Most managers (77\%) have basic training levels, and 21\% have medium training competencies. A study of manager characteristics [15] indicates that university graduate managers outperform their colleagues with secondary education levels. They are more experienced, so they can tackle crises and perform effectively. Based on this, management experience can satisfactorily compensate for educational limitations where the manager does not have a higher education. This means that a manager needs to have a good education and experience to serve customers correctly.

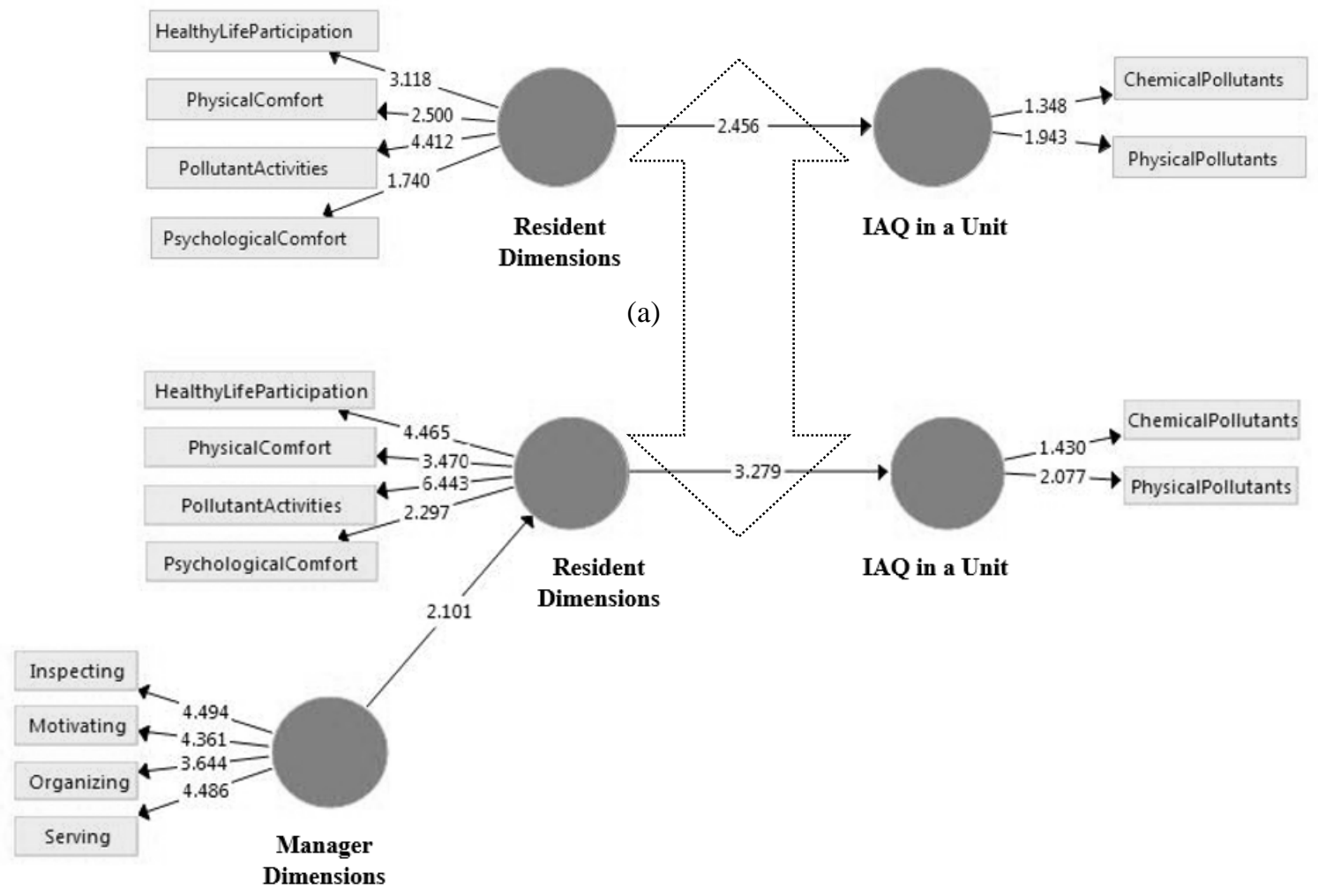

(b)

Fig. 4. The Difference between constructs with (a) or without (b) manager dimensions via PLS

\subsection{SmartPLS Analysis}

This analysis is aimed to assess the differences in the strengths of the influences of 
the latent variables of the construct that affect the IAQ in a resident unit. The latent variables are the resident dimensions as the dependent variables and the IAQ in a unit as the independent variable. The analysis was conducted using the constructs shown in figures 4(a) and 4(b).

Both of constructs in Figure 4 show the different constructs of the partial least square (PLS) among the resident dimensions, manager dimensions, and IAQ in a unit. Figure 4(b) shows the complete construct variables of the resident dimensions, Manager dimensions, and IAQ in a unit and figure 4(a) refers to the PLS construct without the manager dimensions. In the PLS, there are two types of relation value. The inner model shows the relation of the latent variables: the resident dimensions, manager dimensions, and IAQ in a unit. It was found that the difference in the values of both constructs shows that figure 4(b) is better than figure 4(a). Figure 3(b) shows that the inner model values of the resident dimensions to the IAQ in $\mathrm{s}$ unit are stronger at 2.456 to 3.279 than those in figure 4(a).

The results of this study indicate that the manager dimensions in a high rise building can strengthen the influence of the resident dimensions on the IAQ in a unit (2.456 to 3.279). This indicates that the manager dimensions can improve the IAQ in residents' units. Of course, there are other more variables in addition to resident dimensions and manager dimensions that affect the IAQ, such as government policies, etc., which need a more comprehensive study. Spengler has stated that all of the integrated encouragement for sustainable IAQ is called socially responsible investment for designing a healthy living in a high rise building [16,17], such as incentive schemes [4].

The resident-manager dimensions necessary for community engagement for IAQ sustainability in middle-income housing in Jakarta. The local government of Jakarta needs to make a community engagement program a requirement in middle-income housing developments, in addition to administrative, technical, and ecological requirements, for healthy life sustainability [18].

\section{CONCLUSION}

The findings of this research have shown that there is a need for integrated programs for middle-income housing that are driven by the Jakarta Provincial Government. It is suggested that the local government create some policies to serve as behavioral guidance in high-rise residential buildings. This will lead to community empowerment for urban healthy living. The policies will guide planners and company owners to complete a design program. IAQ measurements will become the building evaluation method for future healthy planning [17]. The communities that are going to live in high rise buildings should be engaged in a preparatory program at the beginning of the adjustment period. The building manager will receive some benefits if the residents trust that they are receiving satisfaction from the building. The residents will be easy to invite to the participation program. They would rather live in a healthier atmosphere. The Green Building Council Indonesia (GBCI) has stated that healthy socialization in the form of posters and can include hazard pollution warnings or healthy living role-model program.

This research is more directed at the social aspects of the environment concept. The author proposed to further study the economic [20] and environmental aspects [21]. In addition, future research will evaluate of the local government's representation in managing middle-income housing as healthy living apartments in Jakarta which is related to IAQ sustainability.

\section{ACKNOWLEDGEMENTS}

This work is supported by the Final Assignment Grant for Doctoral Students (Hibah TADOK) 2018 funded by DRPM Universitas Indonesia No. 1371/UN2.R3.1/HKP.05.00/2018 and the Sasakawa Young Leaders Fellowship Fund (SLYFF).

\section{REFERENCES}

[1] Alison OE, Ginny B, Sandy O, Josephine K, Farah $\mathrm{J}$ and James T. The effectiveness of community engagement in public health interventions for disadvantaged groups: a meta-analysis. BMC Health Services Research. 2015.

[2] Alisa JV, Agnes M, Nakia LF, Ashnoor R, Mary B, and Patricia O. One program that could improve health in this neughbourhood is? Using concept mapping to engage communities as part of a health and human services needs assessment. BMC Health Services Research. 2018 Mar 1.

[3] Szylvian KM. The mutual housing experiment: New deal communities for urban middle class. United States: St. John’s University; 2015 Jan 1 (pp. 1-277).

[4] Tridib M, Deepthi C, Anirban M, Koustuv 
D, Amit K, and Ashwin V. CityZen: A cost-Effective City Management System with Incentive-driven Resident Engangement Proc. International Conference on Mobile Data Management/IEEE. 2014 (pp. 290-296).

[5] Michael P K and Mary B. Why is changing health-related behaviour so difficult? Public Health. 2016;136:109-116

[6] Arispe L. Human Dimensions of Global Change, Migration, Women and Social Development. 2014 Aug 5:192-201.

[7] Simona D, Hong T, and Langevin J. The human dimensions of energy use in buildings: A review, Renewable and Sustainable Energy Reviews, 2017 Aug 19; 81:731-742.

[8] Charina Z. Community Engangement: A Summary of Critical Concept. Alberta Health Services; 2012.

[9] Weng ML. Inside the sustainable consumption theoretical toolbox: Critical concepts for sustainability, consumption, and marketing Journal of Business Research. 2017;78:69-80

[10] Stephen A, The human factor: Classification of European communitybased behaviour change initiatives Journal of Cleaner Production. 2018; 182:567-586.

[11] Beth M, Pamela A, Beverley F, Sue P, Margaret W, and Jennie. The impact of community engagement on health and social outcomes: a systematic review Community Development Journal. 2011; 47 (3):316-334.

[12] Wendy BS, Theresa H, Jennifer L, and Marian A. Systematic review of occupational engagement and health outcomes among community-dwelling older adults. The American Journal of Occupational Therapyvol. 2012; 66:301310.

[13] Xiaoping Y, Liying L, Xu W, Xiaoling W, Zhimao W, Qing L, and Guobing S. On a Post-occupancy Evaluation Study of Effects of Occupant Behavior on Indoor Environment Quality in College Buildings in Chongqing. Procedia Engineering. 2017; 205: 623-627.

[14] Muhammad SR, Bashir H, Meshquat U, and Nazrul I. Exploring residents' satisfaction of facilities provided by private apartment companies. Asia Pacific Manajement Review 20 2015; 20:130-140.

[15] Aggelopoulus E. Branch manager characteristics and efficiency during capital controls International Journal of Banking, Accounting and Finance. 2018; 9(1): 44-60.

[16] Kolkailah S. K.,. Aish E. A, El-Bassiouny $\mathrm{N}$. International $\mathrm{J}$. of Consumer Studies. 2012; 36 (4): 369-384.

[17] John D. S. and Qingyan C. Indoor air quality factors in designing a healthy building. Journal of Annual review of energy and the environment. 2000; 25:567600.

[18] Aulia DN, Marpaung BOY, Suryani L. Identification of Increasing Green Behavior in Citraland Bagya City Medan. Proc. IOP Conf. Series: Materials Science and Engineering. 2017; 180: 012087.

[19] Verena MB, Cristina B, Valentina F, and Stefano PC. Occupant behaviour lifestyles and effects on building energy use: Investigation on high and low performing building features. J. Energy Procedia/ Elsevier. 2017; 140: 93-101

[20] Szylvian KM. The mutual housing experiment: New deal communities for urban middle class. United States: St. John's University. Temple University Press. 2015 Jan 1 (pp.1-277).

[21] Thomas P, Jose AGD, and Maria BD. Urban planning with respect to environmental quality and human wellbeing. J. Environmental Pollution/Elsevier. 2016;208:137-144.

Copyright (C) Int. J. of GEOMATE. All rights reserved, including the making of copies unless permission is obtained from the copyright proprietors. 